\title{
Imaging in the Assessment and Management of Overuse Injuries in the Foot and Ankle
}

\author{
James Teh, B.Sc., M.R.C.P., F.R.C.R., ${ }^{1}$ \\ Ravi Suppiah, B.H.B., M.B.Ch.B., P.G. Dip.S.M., 2 \\ Robert Sharp, M.A., F.R.C.S., F.R.C.S.(Trauma \& Orth), ${ }^{3}$ \\ and Julia Newton, M.R.C.P., D.Phil., Dip.S.E.M. ${ }^{2}$
}

\section{ABSTRACT}

Overuse injuries of the ankle and foot are common in the general and athletic populations. The wide spectrum of overuse injuries includes ligamentous injuries, soft tissue and osseous impingement, osteochondral lesions, tendon injuries, and stress fractures. Some conditions such as impingement syndromes and stress fractures may be missed on initial physical examination, and patients with such injuries often present to a sports or orthopedic clinic with persistent symptoms. With the increasing participation in sports, health-care professionals involved in the care of athletes at all levels must have a thorough understanding of overuse conditions of the foot and ankle, and the use of imaging in the management of these conditions. This article covers the clinical presentation, pertinent anatomy, imaging features, and management of overuse injuries of the foot and ankle.

KEYWORDS: Overuse, stress fracture, impingement, tendinopathy, foot, ankle

\begin{abstract}
An overuse injury develops as a consequence of unaccustomed or excessive, repetitive activity. Overuse injuries of the foot and ankle may result in impingement syndromes, tendinopathy, ligament injury, and stress fractures. They are a common cause of pain and disability in the general and athletic population. Many of the conditions are difficult to diagnose clinically, and imaging therefore has a key role in the assessment and management of these patients. Diagnostic pathways tend to vary widely between institutions. In general, plain radiographs should be the initial investigation. For cases of suspected soft tissue injury either magnetic resonance imaging (MRI) or ultrasound may be used according to local expertise. For bone lesions, MRI is generally the investigation of choice, but there are times when computed
\end{abstract}

tomography (CT) should be performed, for example in the context of acute trauma and in the follow-up of stress fractures. This article discusses the clinical presentation, pertinent anatomy, imaging features, and management of overuse injuries of the foot and ankle. Achilles disorders are covered in a separate article.

\section{IMPINGEMENT SYNDROMES}

Impingement syndromes around the ankle may result in a combination of bone, soft tissue, and nerve impingement. They represent an important cause of chronic pain and debility in the athletic population. The diagnosis is usually clinically based, and radiological evaluation is not always necessary. ${ }^{1}$
${ }^{1}$ Department of Radiology, ${ }^{2}$ Department of Sports and Exercise Medicine, ${ }^{3}$ Department of Foot and Ankle Surgery, Nuffield Orthopaedic Centre NHS Trust, Headington, Oxford, United Kingdom.

Address for correspondence and reprint requests: James Teh, M.R.C.P., F.R.C.R., Department of Radiology, Nuffield Orthopaedic Centre NHS Trust, Windmill Road, Headington, Oxford OX3 7LD, UK (e-mail: jamesteh1@googlemail.com).

Sports Injury of the Lower Extremity: Role of Imaging in Diagnosis and Management; Guest Editors, Jeremiah C. Healy, F.R.C.P., F.R.C.R., F.F.S.E.M. and Justin C. Lee, M.R.C.S., F.R.C.R.

Semin Musculoskelet Radiol 2011;15:101-114. Copyright (C) 2011 Thieme Medical Publishers, Inc., 333 Seventh Avenue, New York, NY 10001, USA. Tel: + 1(212) 584-4662.

DOI: http://dx.doi.org/10.1055/s-0031-1271962.

ISSN 1089-7860. 


\section{Posterior Impingement Syndrome}

The typical presentation is of posterior ankle pain of insidious onset in subjects such as ballerinas who regularly perform forced plantar flexion activities. ${ }^{2}$ Radiographs may demonstrate an os trigonum or Stieda process. Ultrasound or MRI may reveal synovial thickening at the posterior aspect of the ankle with hypoechoic nodular thickening and flexor hallucis longus (FHL) tenosynovitis ${ }^{3,4}$ (Fig. 1).

\section{Posteromedial Impingement Syndrome}

Posteromedial ankle impingement syndrome usually follows severe inversion injury in which the deltoid ligament is crushed between the medial malleolus and talus. ${ }^{5} \mathrm{On}$ ultrasound and MRI there is loss of striation of the posterior tibiotalar ligament as well as abnormal signal abutting and encasing the medial tendons ${ }^{6}$ (Fig. 2).

\section{Anterior Impingement Syndrome}

Anterior impingement is a common problem in football players. Typically repeated ankle dorsiflexion activity results in chondral damage, trabecular microfractures, or periosteal hemorrhage, with subsequent anterior spur formation. ${ }^{7}$ Plain radiographs demonstrate anterior spurs and may be the only imaging required. On MRI bone edema, synovitis, and articular cartilage loss may be seen (Fig. 3).

\section{Anterolateral Impingement}

Ankle inversion injury may result in lateral ligament instability, which causes recurrent synovitis and

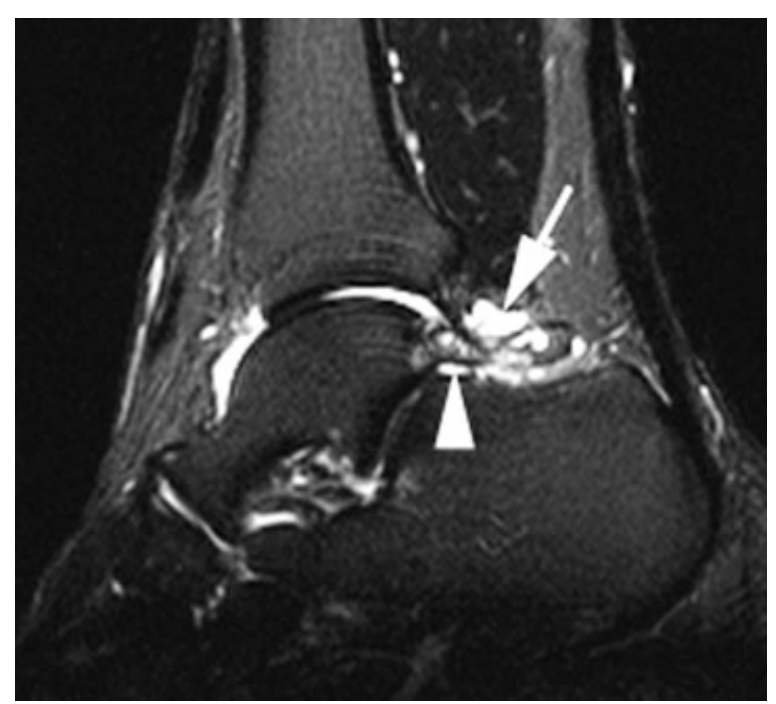

Figure 1 Posterior impingement syndrome. Sagittal short tau inversion recovery image demonstrates bone edema within an os trigonum (arrowhead) with associated synovitis (arrow).

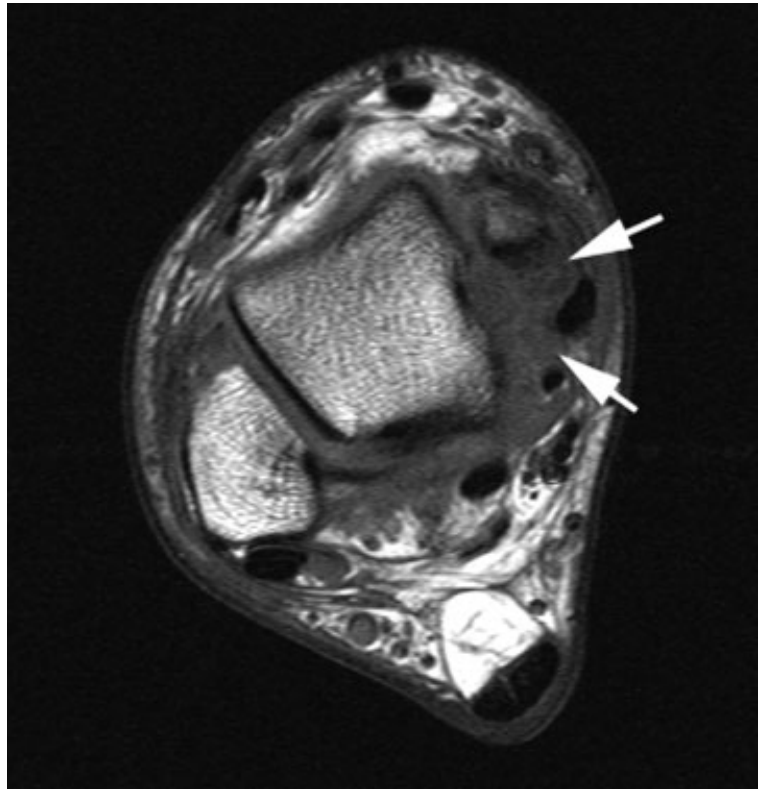

Figure 2 Posteromedial impingement syndrome in a 25-year-old soccer player. Axial T1-weighted image shows posteromedial synovial thickening (arrows) with loss of striation of the tibiotalar ligament.

hemorrhage followed by scarring and synovitis. On MRI there is distension of the anterolateral gutter with capsular irregularity. In advanced cases there may be molding of synovial tissue to form a hyalinized meniscoid lesion, ${ }^{8}$ which may also be seen on ultrasound ${ }^{9}$ (Fig. 4).

\section{Anteromedial Impingement}

Anteromedial impingement is poorly understood but is increasingly recognized. Patients typically give a history

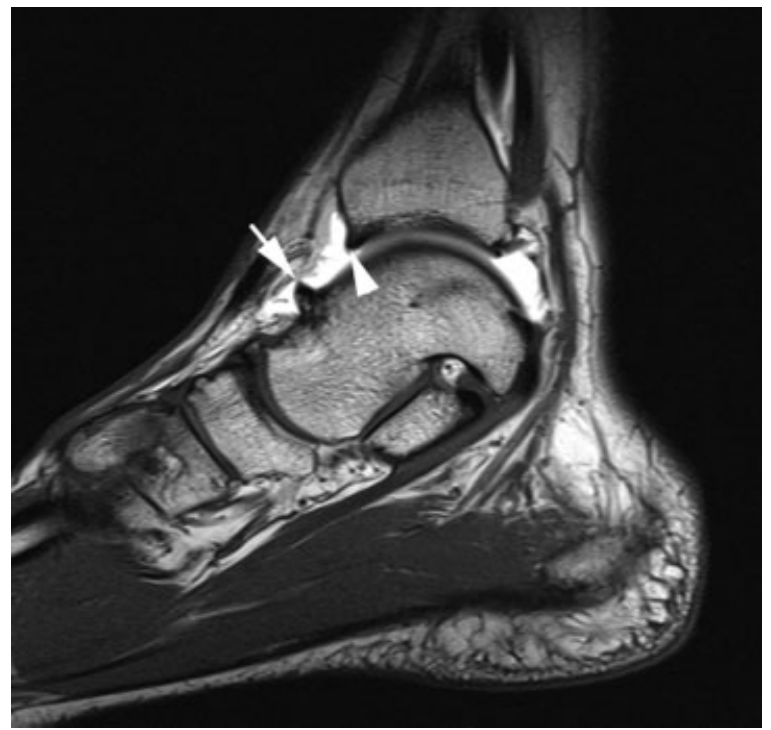

Figure 3 Anterior impingement syndrome. Sagittal T1weighted magnetic resonance arthrogram showing anterior osteophytes (arrow and arrowhead). 


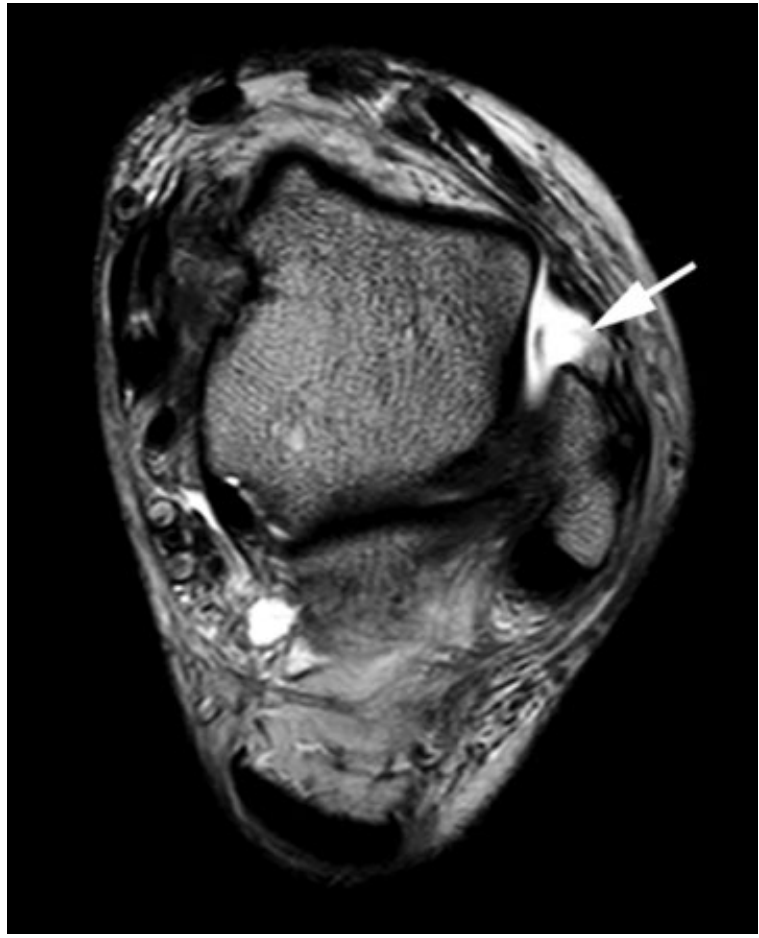

Figure 4 Anterolateral impingement syndrome. Axial T2weighted image demonstrating distension of the anterolateral gutter with synovial stranding (arrow) and laxity of the anterior talofibular ligament.

of supination injury followed by anteromedial pain. Repetitive microtrauma leads to synovitis with anteromedial spur formation. ${ }^{10}$ The imaging findings have not been described on conventional MRI or ultrasound. On MR arthrography, joint distension allows appreciation of irregular anteromedial synovial thickening (Fig. 5).

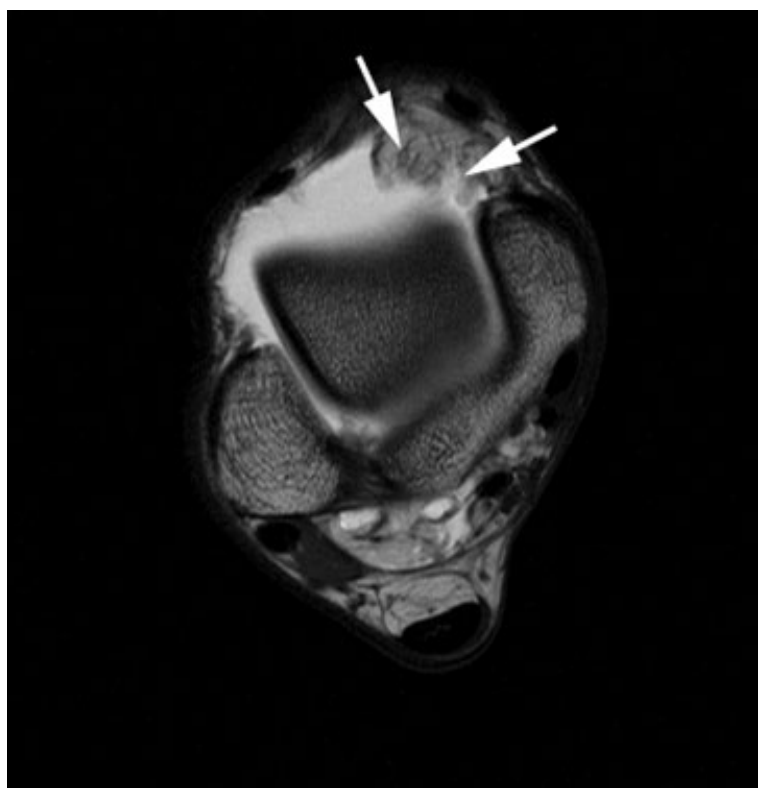

Figure 5 Anteromedial impingement syndrome. Axial T1weighted magnetic resonance arthrogram showing distension of the anterior joint space with anteromedial synovitis (arrows).

\section{Management of Impingement Syndromes}

Relative rest from the culprit activity and physiotherapy should be integral to the management. Image-guided injection may give lasting relief. In resistant cases, especially when imaging studies demonstrate bony structures contributing to impingement, surgery may be required.

\section{SINUS TARSI SYNDROME}

\section{Presentation}

Sinus tarsi syndrome is characterized by focal pain and tenderness in the sinus tarsi that is responsive to injection of local anesthetic. The symptoms are often associated with a feeling of instability and aggravation by weightbearing activity. Most cases arise following trauma, but the syndrome can be associated with inflammatory arthritis or foot deformities such as pes planus. $^{11}$

\section{Anatomy and Imaging}

The sinus tarsi is a cone-shaped cavity located between the neck of the talus and the anterosuperior surface of the calcaneus. It contains fat, vessels, nerves, and ligaments. With sinus tarsi syndrome there is replacement of normal fat signal intensity in the sinus tarsi with fluid or inflammatory tissue, with resultant low T1 signal intensity and high $\mathrm{T} 2$ signal intensity ${ }^{11}$ (Fig. 6). Associated features include lateral ligament tears, tibialis posterior tendon tears, and ganglia arising from the posterior subtalar joint. ${ }^{12}$

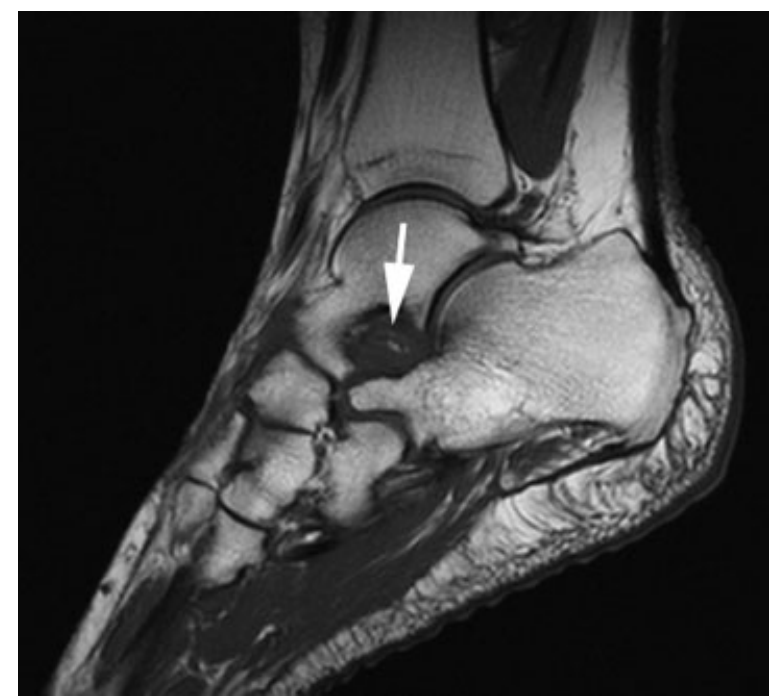

Figure 6 Sinus tarsi syndrome. Sagittal T1-weighted image demonstrating complete replacement of the fat signal within the sinus tarsi (arrow). 


\section{Management}

Conservative treatment consists of corticosteroid injections, along with physiotherapy and correction of foot biomechanics. Sinus tarsectomy or subtalar joint synovectomy is reserved for persistent symptoms. ${ }^{13}$

\section{TARSAL TUNNEL SYNDROME}

\section{Clinical Presentation}

Tarsal tunnel syndrome refers to an entrapment neuropathy of the posterior tibial nerve or its branches as they transverse the tarsal tunnel. ${ }^{14}$ Trauma, tarsal coalition, or any space-occupying lesion may cause the syndrome. Repetitive overpronation that can occur on the inside foot of a track runner is also recognized as a predisposing factor. Patients complain of paraesthesia or a burning sensation over the heel, plantar surface of the foot, and first three toes. A positive Tinel's test may be present. Nerve conduction testing can be useful because the symptoms are often nonspecific.

\section{Anatomy and Imaging}

The tarsal tunnel is a continuation of the deep posterior compartment of the lower leg into the medial aspect of the foot. ${ }^{14}$ The medial ankle tendons and neurovascular bundle pass through the tunnel. The tibial nerve divides into terminal branches of the medial calcaneal nerve and the medial and lateral plantar nerve. Imaging is used to exclude space-occupying lesions such as ganglia, nerve sheath tumors, tendinopathy, accessory muscles, or varicosities (Fig. 7).

\section{Management}

Rest, orthotics and steroid injections into the tarsal tunnel may be beneficial. Even in the absence of a mass lesion, surgical decompression may be curative.

\section{TENDON PATHOLOGY}

\section{Peroneal Tendons}

\section{CLINICAL PRESENTATION}

Peroneal tendon injuries should be considered in all patients who present with chronic lateral ankle pain. The main conditions affecting the peroneal tendons are tenosynovitis, tendinosis, tendon tears, and tendon subluxation.

\section{PERONEAL TENDINOPATHY}

Peroneal tendinopathy is closely linked to lateral ligamentous injury. Anatomical variations such as a shallow retromalleolar groove, a low-lying muscle belly, an

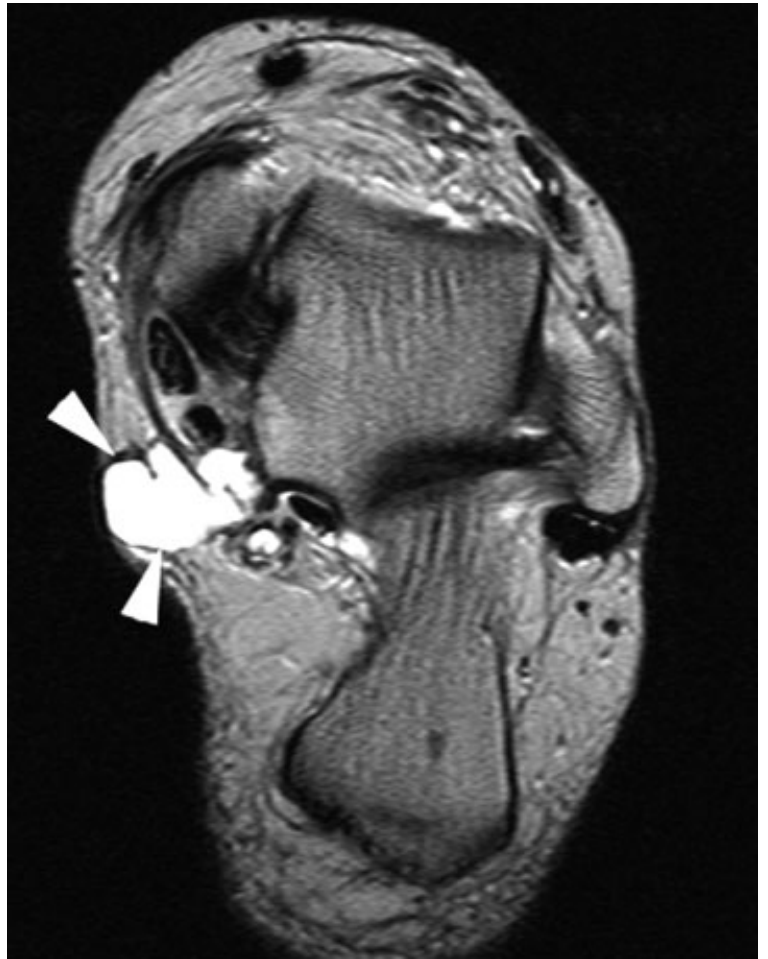

Figure 7 Tarsal tunnel syndrome. Axial T2-weighted image demonstrating a ganglion within the tarsal tunnel (arrowheads).

accessory peroneus quartus, or enlarged peroneal tubercle are associated with peroneal tendinopathy. ${ }^{15} \mathrm{On}$ MRI, thickening or altered signal in the tendon indicates tendinosis. On ultrasound, there may be loss of the normal fibrillar structure of the tendon with areas of altered echogenicity and increased vascularity on Doppler (Fig. 8). If the cross-sectional area of tendon sheath fluid is greater than that of the tendon or if complex fluid is present, tenosynovitis can be diagnosed. Impingement

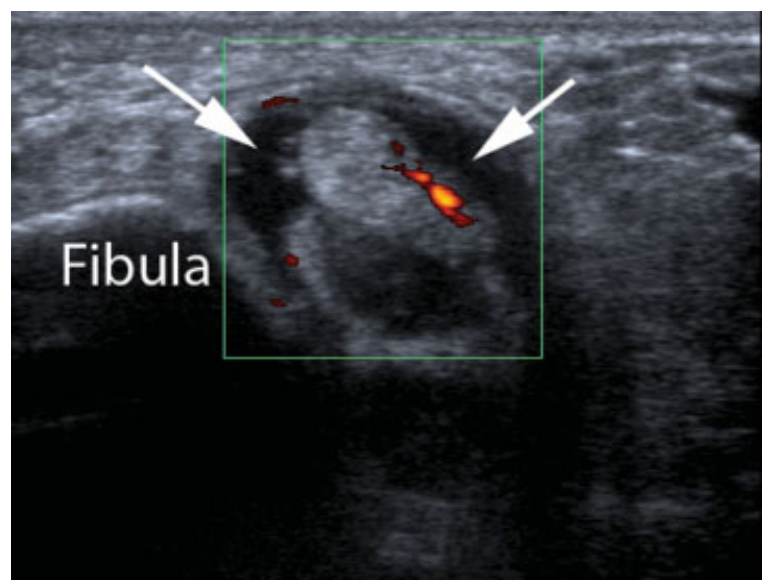

Figure 8 Peroneal tenosynovitis. Transverse ultrasound at the level of the lateral malleolus indicating peroneal tenosynovitis (arrows) with minor increased vascularity on Doppler. 
of the tendon may occur at the level of the cuboid as the peroneus longus courses through the cuboid tunnel ${ }^{16}$ (Fig. 9). If there is fluid signal within the substance of the tendon, loss of continuity of fibers or nonvisualization of the tendon, a tear should be considered.

\section{PERONEAL TENDON SPLITS}

Chronic impingement of the peroneus brevis between the fibula and peroneus longus may result in a peroneus brevis split. In the early stages the peroneus brevis becomes boomerang shaped, with the peroneus longus lying in the concavity. Eventually the peroneus brevis may be seen as two separate structures on either side of the peroneus longus on axial images ${ }^{17}$ (Fig. 10). Peroneus longus tears can occur with peroneus brevis tears at the level of the lateral malleolus or be isolated at the level of the midfoot.

Painful os peroneum syndrome (POPS) describes a spectrum of disorders caused by chronic repetitive injury that occurs in patients who have an os peroneum. The syndrome may be associated with a fracture of the os peroneum, with tenosynovitis or tendinosis. ${ }^{18} \mathrm{~A}$ peroneus longus tear may occur near the os peroneum with retraction of the os, which normally is situated at the level of the calcaneocuboid joint. ${ }^{19}$ Os peroneum fragment separation of $\geq 6 \mathrm{~mm}$ suggests an os peroneum fracture with a peroneus longus tendon tear. ${ }^{19}$

\section{PERONEAL SUBLUXATION}

Peroneal tendon subluxation usually occurs as a result of peroneal retinaculum injury. A hypoplastic peroneal fibular groove may also play a role. Subluxation may

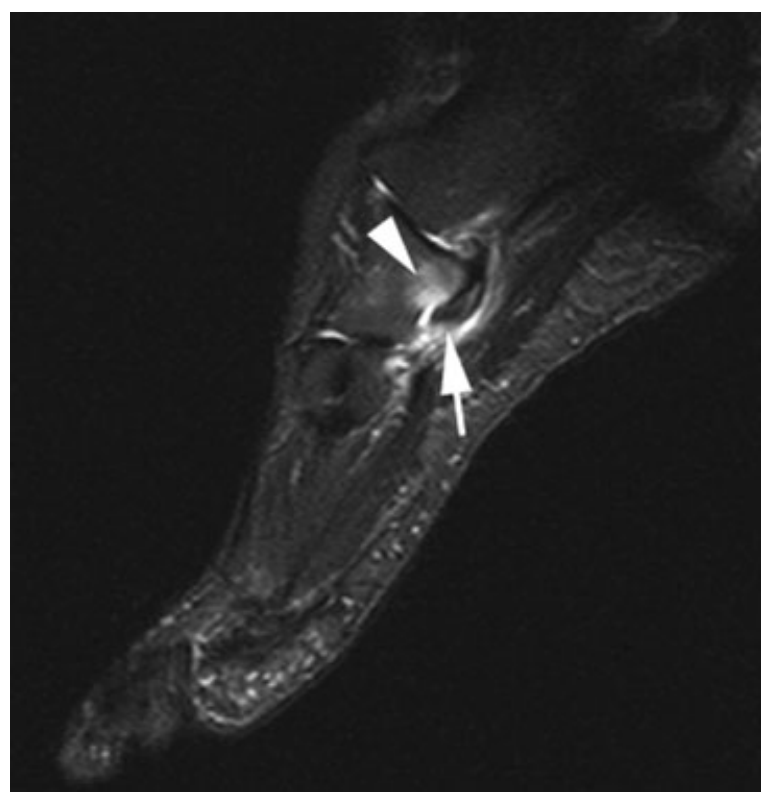

Figure 9 Cuboid tunnel syndrome. Sagittal short tau inversion recovery image demonstrating peroneus longus tenosynovitis at the level of the cuboid (arrow), with bone edema in the cuboid (arrowhead).

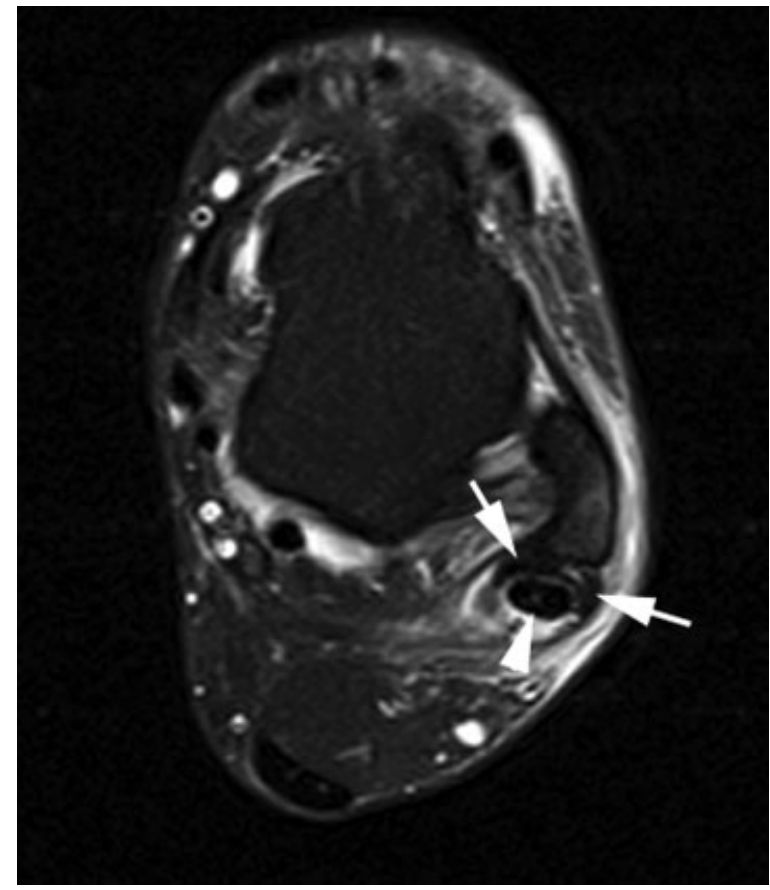

Figure 10 Peroneus brevis split. Axial T2 fat-saturated image demonstrating a longitudinal split of peroneus brevis (arrows), with the split tendon lying on either side of the peroneus longus tendon (arrowhead).

not be seen on static MRI. Therefore, if peroneal subluxation is suspected, dynamic ultrasound is the preferred imaging modality. ${ }^{20}$ Either or both peroneal tendons may sublux. The tendons may remain in the retromalleolar groove but can reverse their positions, a condition described as retromalleolar intrasheath dislocation (Figs. 11 and 12).

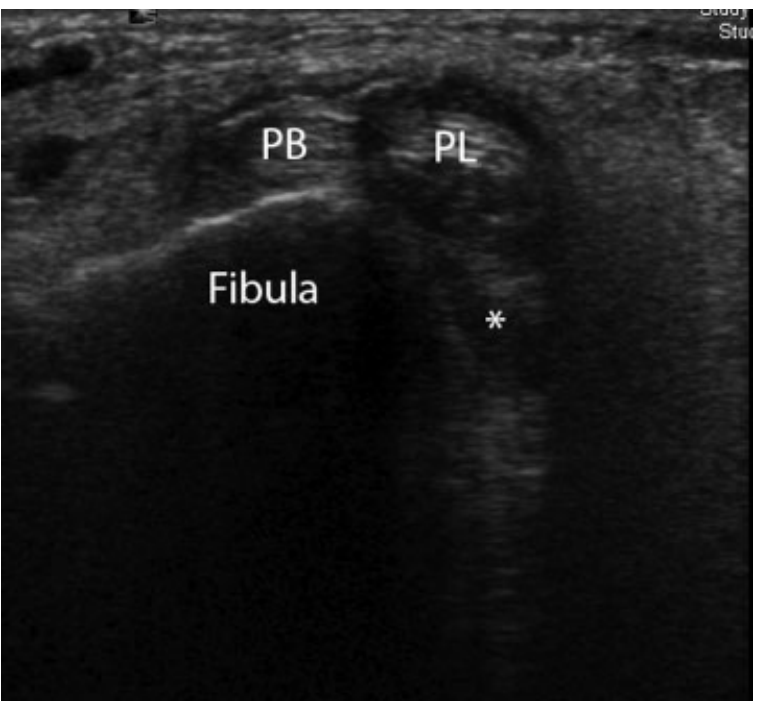

Figure 11 Peroneal subluxation. Transverse ultrasound scan at the level of the lateral malleolus demonstrating anterior subluxation of the peroneus brevis (PB) and peroneus longus $(\mathrm{PL})$ tendons. The asterisk shows the normal position of the tendons. 


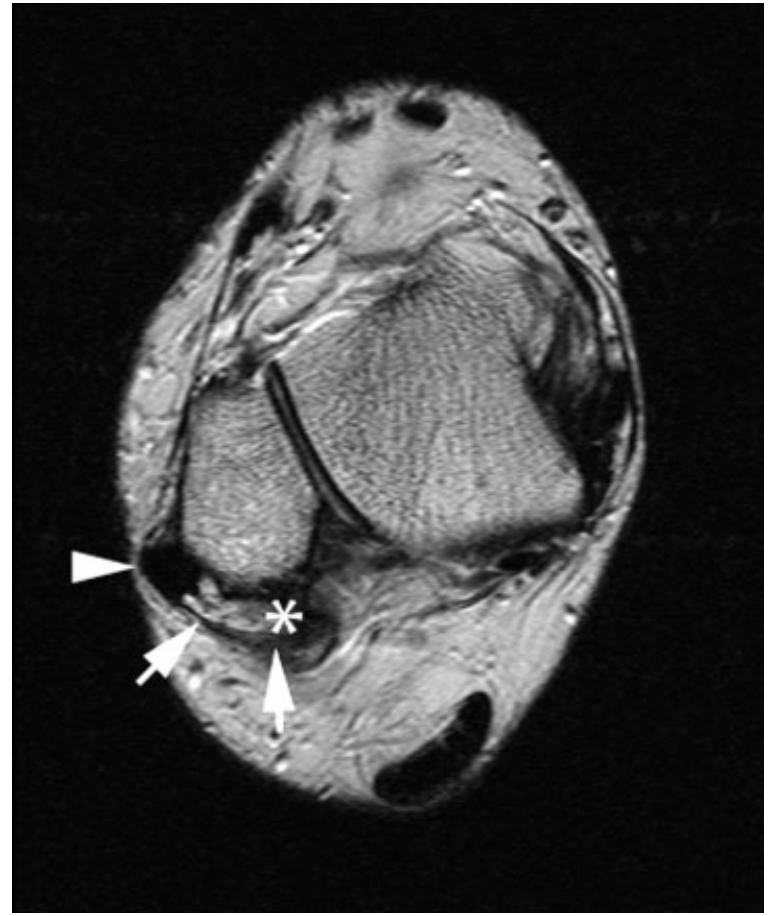

Figure 12 Peroneal subluxation. Axial T2-weighted image demonstrating a lax peroneal retinaculum (short arrows) and laterally subluxed peroneal tendons (arrowhead). The asterisk shows the normal position of the tendons.

\section{MANAGEMENT}

Peroneal tendinopathy is usually treated conservatively with rest, orthotics, and resistance exercises. Injections may result in tendon rupture and are therefore not recommended. Conservative management may be attempted in acute dislocations, although operative management is preferred in athletes. Recurrent dislocations should be managed surgically.

\section{Tibialis Posterior Tendon and Spring Ligament}

\section{CLINICAL PRESENTATION}

Tibialis posterior dysfunction is an overuse condition that is more common in middle-aged women, the obese, and people with diabetes. ${ }^{21}$ Patients usually present with medial pain and swelling with gradual loss of the plantar arch, resulting in pes planus.

\section{TIBIALIS POSTERIOR TENDINOPATHY}

The tibialis posterior acts as an important stabilizer of the arch and is the main everter of the foot. Tendinosis may be diagnosed if the tendon is thickened or if there is altered texture. Distinction between severe tendinosis and partial tears may be difficult due to morphological overlap between the two conditions. The presence of intrasubstance longitudinal splits indicates a type 1 tear. The normal tibialis posterior tendon is around twice the size of the adjacent flexor digitorum longus tendon. A tibialis posterior tendon that is the same size or smaller than the adjacent flexor digitorum tendon indicates chronic attrition and partial tearing (type 2 tear). With complete tears, a gap and tendon retraction may be evident (type 3 tear). Tibialis posterior tendinopathy is commonly associated with injury to the calcaneonavicular portion of the spring ligament and sinus $\operatorname{tarsi}^{22}$ (Fig. 13). On MRI the spring ligament is best seen on axial images and should appear as a low signal structure on all sequences, extending from the sustentaculum to the navicular, lying deep to the tibialis posterior tendon. ${ }^{23}$ On ultrasound there is a striated appearance with no flow on Doppler. ${ }^{24}$ Insufficiency of the spring ligament is usually manifest by thickening and laxity, with blurring of the margins.

\section{MANAGEMENT}

Nonoperative treatment of tibialis posterior tendinopathy includes orthotics and physiotherapy. Injections are not advised due to the increased risk of tendon rupture. Operative treatment of early-stage disease includes tenosynovectomy, with debridement or repair of tears. ${ }^{21}$ With more advanced disease, tendon transfer, usually with the flexor digitorum longus, is performed in conjunction with a calcaneal osteotomy. The most severe cases may require hindfoot fusion.

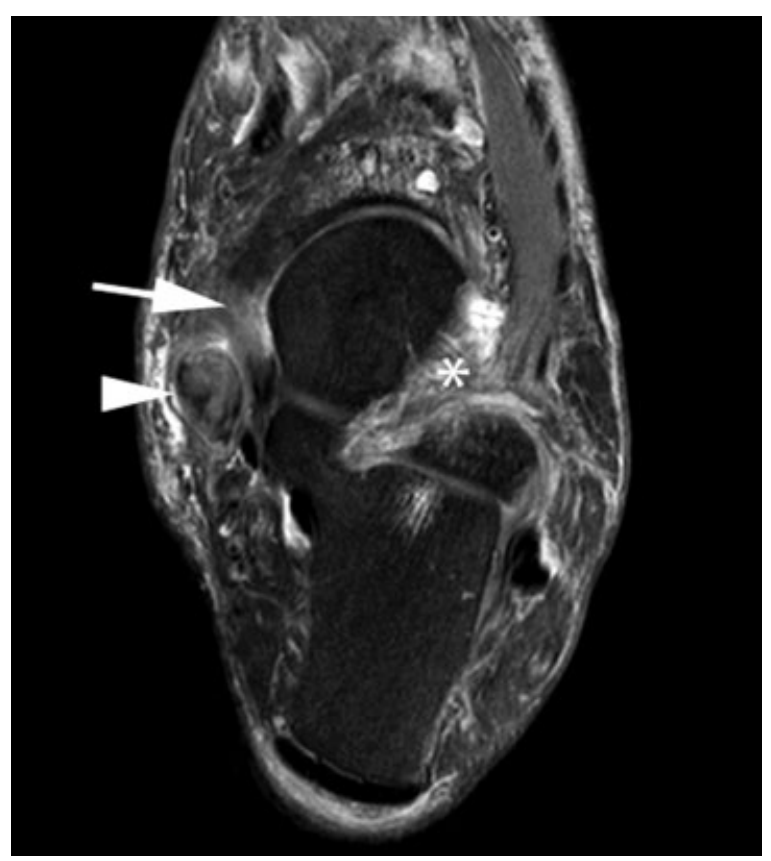

Figure 13 Tibialis posterior tendinopathy with spring ligament insufficiency and sinus tarsi syndrome. Axial oblique T2 fat-saturated image showing a markedly swollen, partially torn tibialis posterior tendon with altered signal (arrowhead), a lax spring ligament with increased signal (arrow), and edema in the sinus tarsi (asterisk). 


\section{Painful Accessory Navicular}

\section{CLINICAL PRESENTATION}

The accessory navicular is one of the commonest accessory ossicles of the foot. Although usually asymptomatic, there may be pain, swelling, and localized tenderness.

\section{ANATOMY AND IMAGING}

Three types of accessory navicular bone are described: ${ }^{25}$ Type $I$ is a sesamoid bone within the posterior tibial tendon, anatomically separate from the navicular. Type II is an accessory ossification center lying medial to the navicular. It is bridged by a fibrocartilaginous synchondrosis to the navicular bone and serves as the point of attachment for the tibialis posterior tendon. Type III is a fused or partly fused accessory navicular, forming a cornuate navicular. Type II is the most commonly symptomatic variant, presenting with localized medial foot pain and tenderness with associated soft tissue inflammation. Radiographs may be all that is required to confirm the clinical suspicion. Ultrasound allows evaluation of the tibialis posterior tendon insertion and comparison with the contralateral side but is unable to determine the presence of bony stress change. Bone scintigraphy has a high sensitivity but lacks specificity. MRI is the examination of choice for demonstrating both bone changes and tibialis posterior tendinosis ${ }^{26}$ (Fig. 14).

\section{MANAGEMENT}

If conservative management is not successful, the accessory ossicle can be fused or removed.

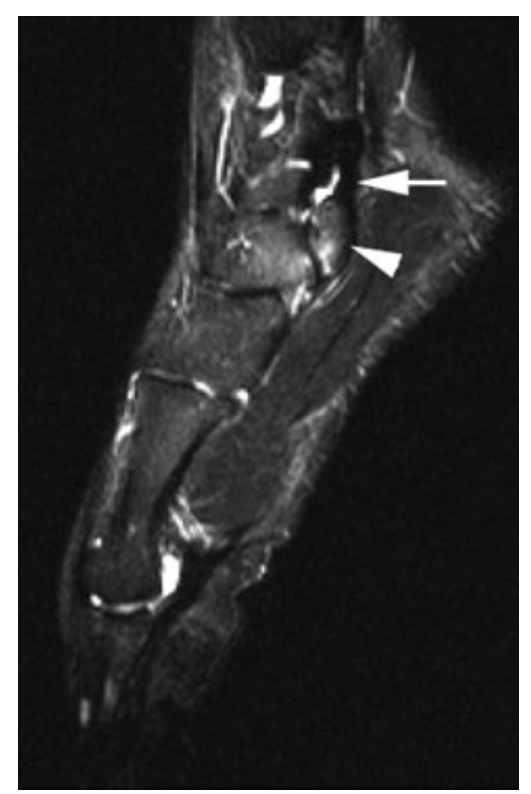

Figure 14 Symptomatic type 2 accessory navicular. Sagittal short tau inversion recovery image demonstrating a type 2 accessory navicular (arrowhead) with minor bone edema at the synchondrosis. The tibialis posterior tendon (arrow) appears normal.

\section{Extensor Tendons}

Closed injuries of the extensor tendons are uncommon. The anterior tibial tendon can be injured by friction against the inferior extensor retinaculum, talonavicular osteophytes, or bony excrescences, leading to tenosynovitis or rupture. Downhill runners, football players, and skiers who are subject to forced plantar flexion may be susceptible. The typical presentation for anterior tibial tendon rupture is localized pain with a foot drop. Characteristic MRI findings include tendon thickening $(>5 \mathrm{~mm})$ and diffuse or signal abnormalities of the tendon. ${ }^{27}$ Ultrasound also allows excellent depiction of tibialis anterior tendinopathy and is useful for marking the extent of tendon retraction before surgery in cases of rupture. The stump may retract to the level of the ankle joint, with fluid or scar tissue filling the gap.

\section{PLANTAR FASCIA LESIONS}

\section{Plantar Fasciitis}

\section{CLINICAL PRESENTATION}

Plantar fasciitis is the most common cause of heel pain and tenderness. Runners and obese patients are frequently affected, as are patients with seronegative arthropathy. Discomfort is usually worst during the first few steps in the morning and improves with movement initially but then deteriorates with continued activity.

\section{ANATOMY AND IMAGING}

The plantar fascia is the most important structure for supporting the longitudinal arch. ${ }^{28}$ Repetitive activity results in microtears and traction at the enthesis, which heals by fibroblastic proliferation, resulting in thickening. The central and medial bundles are most commonly involved. Plantar calcaneal spurs are often seen, but the finding is present in up to $25 \%$ of the asymptomatic population. On sagittal MRI the plantar fascia is visualized as a well-defined 2- to 4-mm-thick low signal band on all sequences. The main feature of plantar fasciitis on MRI is fusiform swelling at the calcaneal insertion. ${ }^{29}$ Focal bone edema may be present. The associated inflammatory reaction can cause entrapment of the lateral plantar nerve (Baxter's neuropathy), which manifests as denervation of the abductor digiti minimi muscle. On ultrasound the plantar fascia has an echogenic fibrillar structure, and it is best assessed in the longitudinal plane. ${ }^{28}$ With plantar fasciitis there is fusiform thickening, with focal or generalized loss of reflectivity. Entheseal new bone formation or spur formation may be seen (Fig. 15).

\section{MANAGEMENT}

Conservative therapy includes rest, physiotherapy, and massage. Orthotics should be prescribed to provide local 


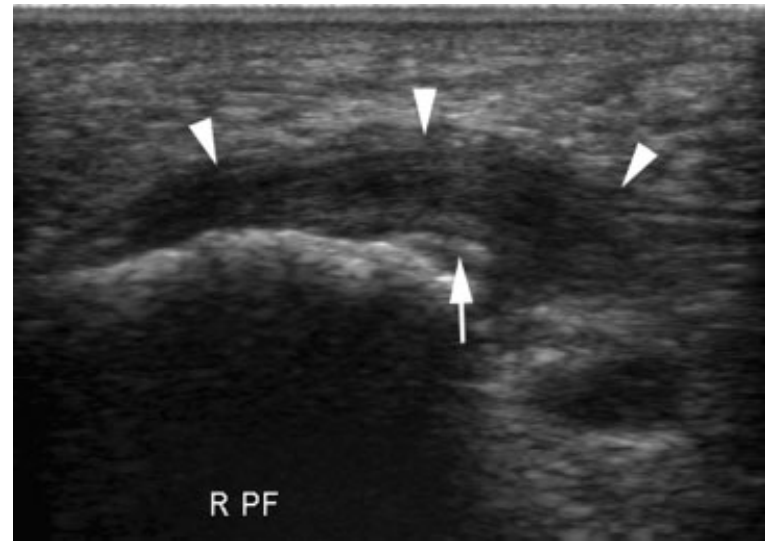

Figure 15 Plantar fasciitis. Longitudinal ultrasound scan demonstrating a swollen plantar fascia insertion (arrowheads) with enthesopathic change (arrow).

comfort and correct gait disturbances. Corticosteroid injections and dry needling can improve symptoms, but meta-analysis shows no good evidence for sustained improvement. ${ }^{30}$ Injections are associated with a risk of fascial rupture and fat pad atrophy. Extracorporeal shock wave therapy using a variety of techniques has been shown to give modest benefit. Plantar fascia release is the last resort in treatment.

\section{Plantar Fascia Rupture}

\section{CLINICAL PRESENTATION}

Plantar fascia rupture may occur in the context of overuse in patients with underlying plantar fasciitis or as an acute injury in running or jumping athletes. There is a strong association with previous steroid injections. Patients usually experience a pop with a tearing pain, followed by swelling.

\section{IMAGING}

On MRI there is interruption of the low signal plantar fascia with high signal intensity on a short tau inversion recovery (STIR) or T2 fat-saturated sequence. ${ }^{28}$ Most tears occur close to the calcaneal insertion. In the acute phase there is usually surrounding soft tissue high signal indicating edema and hemorrhage. On ultrasound there is loss of continuity of the plantar fascia with loss of the normal fibrillar structure, with hypoechoic tissue around the injury indicating edema and hemorrhage.

\section{MANAGEMENT}

The treatment protocol usually comprises 2 to 3 weeks of nonweightbearing in a removable boot followed by protected weightbearing for 1 to 3 weeks. This may be combined with ultrasound therapy, ice, and deep massage.

\section{Table 1 Classification of Osteochondral Lesions}

\begin{tabular}{ll}
\hline Stage 1 & $\begin{array}{c}\text { Subchondral bone edema with intact overlying } \\
\text { cartilage }\end{array}$ \\
Stage 2 & Partially detached stable osteochondral fragment \\
Stage 3 & Completely detached but in situ fragment \\
Stage 4 & Displaced osteochondral fragment \\
\hline
\end{tabular}

Adapted from Berndt and Harty. ${ }^{31}$

\section{Osteochondral Injury}

\section{CLINICAL PRESENTATION}

Osteochondral lesions of the talar dome are referred to as osteochondritis dissecans, osteochondral defects, and osteochondral fractures. They are usually due to impaction following twisting injury of the ankle. ${ }^{31}$ Some lesions are related to repetitive stress, abnormal stress due to instability, or microemboli resulting in infarcts. They present with ankle pain, swelling, and dysfunction. Early recognition is important because premature osteoarthritis may occur.

\section{IMAGING}

MRI is useful for detecting the presence, location, and size of the lesion, as well as assessing the integrity of the overlying cartilage, the degree of attachment, and the location and viability of fragments. Treatment is based on the degree of detachment of the osteochondral fragment and therefore requires precise classification. Osteochondral lesions have been classified into four stages (Berndt and Harty classification) based on radiographic and surgical findings ${ }^{31}$ (Table 1). Using arthroscopy as the gold standard, Mintz et al described diseasenegative (grades 0 and 1 ) and disease-positive (grades 2 to 5) status, and found that MRI had a sensitivity of $95 \%$ and a specificity of $100 \%$ (Table 2). Medial talar dome lesions tend to occur following inversion injury with impaction of the tibia against the posteromedial dome, giving a cup-shaped lesion (Fig. 16). Lateral lesions follow inversion injury with the foot in dorsiflexion giving thinner, more wafer-like lesions, which tend to be more symptomatic and unstable than medial lesions (Fig. 17). A high T2 signal intensity interface between the normal bone and the fragment suggests instability, whereas low signal suggests healing. ${ }^{32}$ Focal defects of the overlying cartilage and cyst like lesions at the inter-

\section{Table 2 Grading of Osteochondral Lesions}

\begin{tabular}{ll}
\hline 0 & Normal cartilage \\
1 & Abnormal signal but intact cartilage \\
2 & Fibrillation or fissures not extending to bone \\
3 & Flap present or bone exposed \\
4 & Loose undisplaced fragment \\
5 & Displaced fragment \\
\hline
\end{tabular}

Adapted from Mintz et al. ${ }^{46}$ 


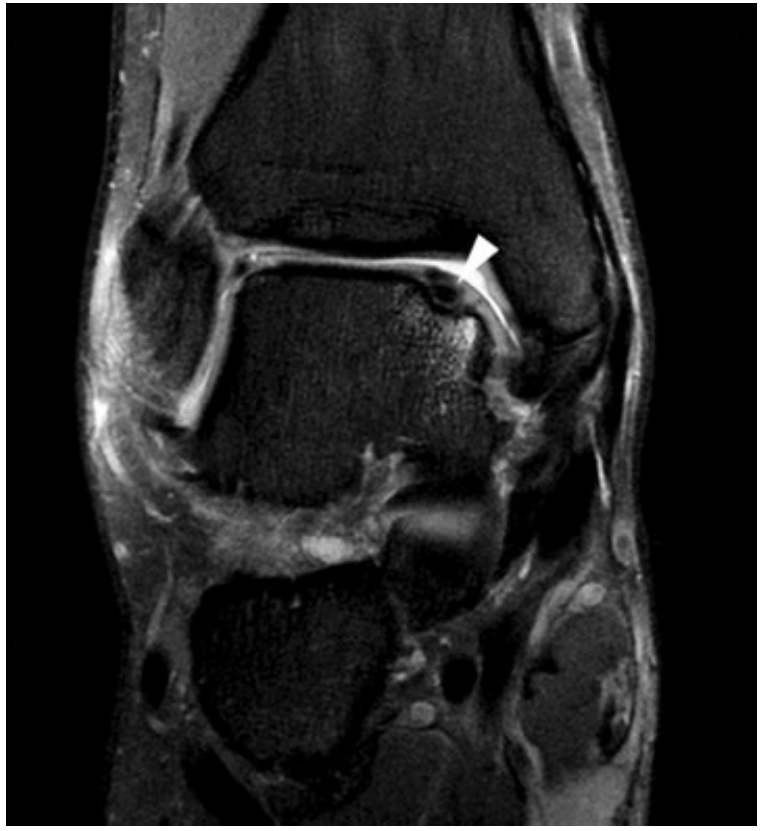

Figure 16 Medial talar dome osteochondral lesion with in situ fragment. Coronal proton-density fat-saturated sequence showing a cup-shaped lesion with a low signal in situ fragment (arrowhead).

face between the fragment and the bone are also features of instability. If the fragment is of low signal intensity on all sequences, osteonecrosis is likely, whereas if normal marrow signal is seen on a T1-weighted image, it

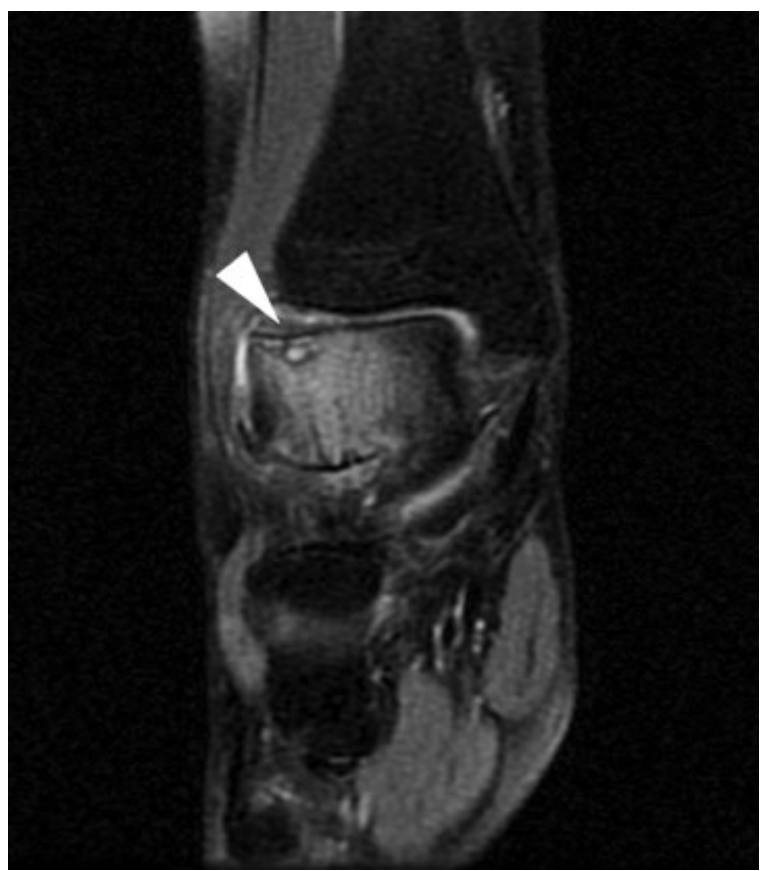

Figure 17 Lateral talar dome lesion. Coronal proton-density fat-saturated sequence showing a wafer-like osteochondral lesion (arrowhead) with a low signal subchondral fracture line and early cyst formation. suggests the presence of viable bone marrow. ${ }^{33}$ Administering intravenous gadolinium can further assess viability. If the fragment enhances, it indicates vascularized viable tissue. CT may allow accurate delineation of the fragment and assess the degree of detachment (Fig. 18). The accuracy of grading of osteochondral lesions is improved by arthrography. If contrast is interposed between the fragment and the donor site, it indicates instability.

\section{MANAGEMENT}

The treatment aims are to promote revascularization and healing and to prevent detachment of the fragment. Nonoperative management is recommended when the cartilage is intact and the lesion is considered stable. Operative treatment is advocated for unstable lesions, particularly when there is articular incongruity or osteonecrosis of the fragment. ${ }^{34}$ Arthroscopic microdrilling and open procedures, such as osteochondral autograft transfer system and autologous chondrocyte implantation, may be employed.

\section{Stress Fractures}

\section{CLINICAL PRESENTATION}

Stress fractures may be categorized into fatigue and insufficiency fractures. Fatigue fractures occur due to continuous repetitive strain in normal healthy bone. They usually occur in athletes who have rapidly increased their training or in subjects such as military recruits who undertake unaccustomed exercise. Insufficiency fractures

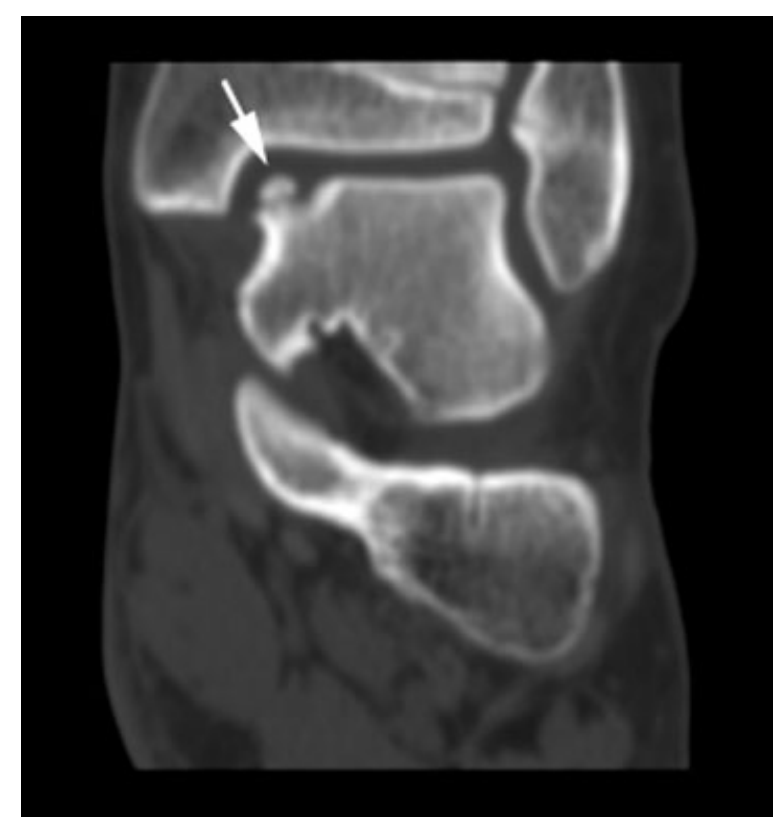

Figure 18 Medial talar dome lesion. Computed tomography with coronal reformat showing a well-defined in situ fragment (arrow). 
occur due to normal activity in bone that is mineral deficient. They usually occur in elderly osteoporotic women but can occur in younger patients with underlying hormonal, nutritional, or metabolic disorders. The presentation is typically of localized pain on impact, which settles with rest.

\section{PATHOGENESIS AND IMAGING}

A stress reaction occurs as the first stage in the development of a stress fracture. This manifests as edema and hyperemia. As the injury progresses, an irregular, often incomplete break may occur. Usually the fracture runs perpendicular to the cortex. Shortly after the fracture occurs, periosteal callus is laid down, followed by cortical thickening and irregularity. Eventually there is bony remodeling.

\section{Plain Radiographs}

The first-line investigation for a suspected stress fracture should be the plain radiograph because they are useful if positive and help rule out other conditions. However, the sensitivity of radiographs for detecting early stress fractures is relatively poor, ranging from 15 to $56 \% .^{35,36}$ Therefore, if the clinical features are suggestive but initial radiographs are negative, the index of suspicion should remain high and further imaging should be performed. Follow-up radiographs usually show callus formation and are therefore useful for assessing the evolution stress fractures. Early stress injury in cortical bone results in poor definition of the cortex and faint intracortical lucent striations. This is followed by periosteal reaction and endosteal thickening as buttressing occurs. Eventually a radiolucent cortical fracture line becomes visible.

\section{Magnetic Resonance Imaging}

MRI is superior to other modalities for the evaluation of stress fractures with its excellent contrast resolution, multiplanar capability, and lack of ionizing radiation. MRI has been shown to be more sensitive than $\mathrm{CT}$ and scintigraphy ( $88 \%$ compared with $42 \%$ and $74 \%$, respectively) for detection of tibial stress fractures. ${ }^{37}$ Routine examination should include T1-weighted and edemasensitive sequences in at least two orthogonal planes. Intravenous gadolinium is not usually required but may improve sensitivity. Initially there is bone, periosteal, and soft tissue edema that is only demonstrated on edemasensitive sequences. A stress reaction appears as poorly defined abnormal signal intensity within the bone marrow similar to that of a bone contusion with intermediate/low intensity on T1-weighted images and high signal on STIR. ${ }^{38}$ Eventually a fracture line appears as a band of linear decreased signal intensity extending perpendicular to the cortex into the medullary canal.
Surrounding bone and soft tissue edema is usually present.

\section{Bone Scintigraphy}

Before the advent of MRI, bone scintigraphy using technetiucm-99m analogs was the gold standard for diagnosing early stress fractures. Scintigraphy demonstrates increased bone uptake at sites of increased osteoblastic activity before changes on plain radiographs and $\mathrm{CT},{ }^{35}$ becoming positive within 72 hours of injury, with a sensitivity approaching 100\%. However, tumors, infection, and bone infarction can cause false positives, so correlation with other imaging modalities is essential. Scintigraphy is of particular value when MRI cannot be performed.

\section{Computed Tomography}

CT can identify subtle cortical abnormalities associated with stress fractures such as periostitis, osteopenia, cortical lucency, and bony bridging. CT has an important role in the evaluation and healing of stress fractures of the foot, particularly those involving the navicular ${ }^{39}$ (Fig. 19). CT can also characterize lesions such as osteoid osteomas by visualization of the nidus. ${ }^{35}$

\section{Ultrasound}

Ultrasound can detect cortical breaks and periosteal reactions but is not routinely used for the primary diagnosis of stress fractures. The periosteal reaction associated with metatarsal stress fractures can be demonstrated before changes on radiographs. On Doppler, increased vascularity may be present around the fracture site (Fig. 20).

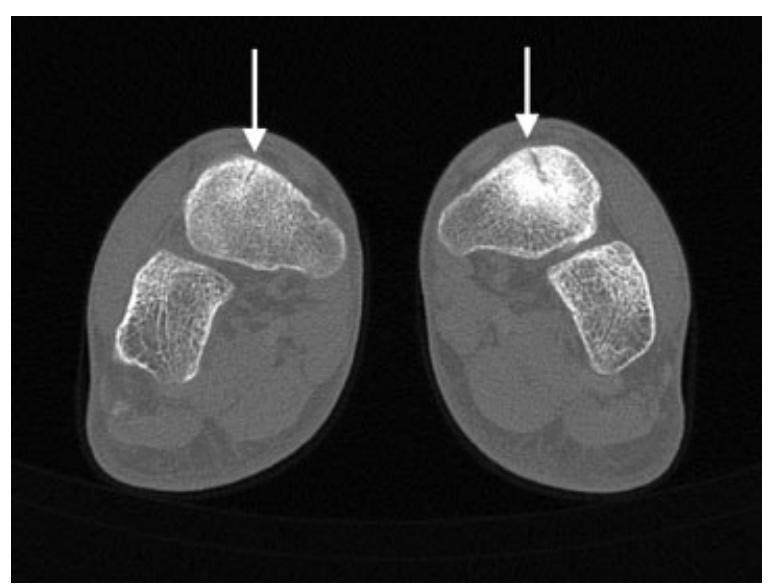

Figure 19 Bilateral navicular stress fractures. Coronal computed tomography scan showing bilateral fracture lines (arrows) in the sagittal plane with surrounding sclerosis. 


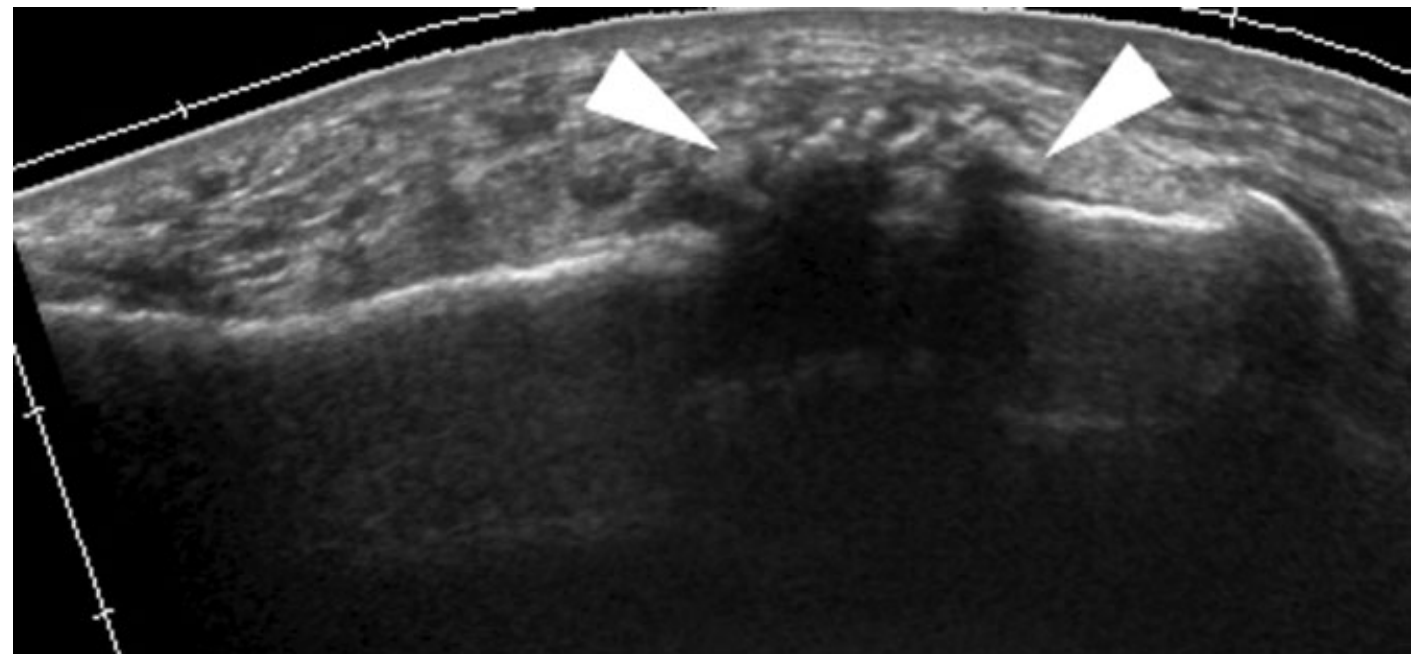

Figure 20 Metatarsal stress fracture. Longitudinal extended field-of-view ultrasound image showing periosteal reaction (arrowheads) at the fracture site.

\section{STRESS FRACTURES AFFECTING THE FOOT}

Metatarsal stress fractures, or march fractures, usually affect the shaft of the second and third rays. Stress fractures localized at the base of the second or third metatarsals are classically seen in ballet dancers. Stress fractures of the fifth metatarsal shaft usually occur in the proximal third.

Calcaneal stress fractures may be missed on up to $85 \%$ of cases on radiographs. ${ }^{40}$ When visible they typically appear as a thin band of sclerosis that parallels the posterior cortical margin running perpendicular to the trabeculae. Most fractures occur in the posterior part of the calcaneus (Fig. 21). Anterior process

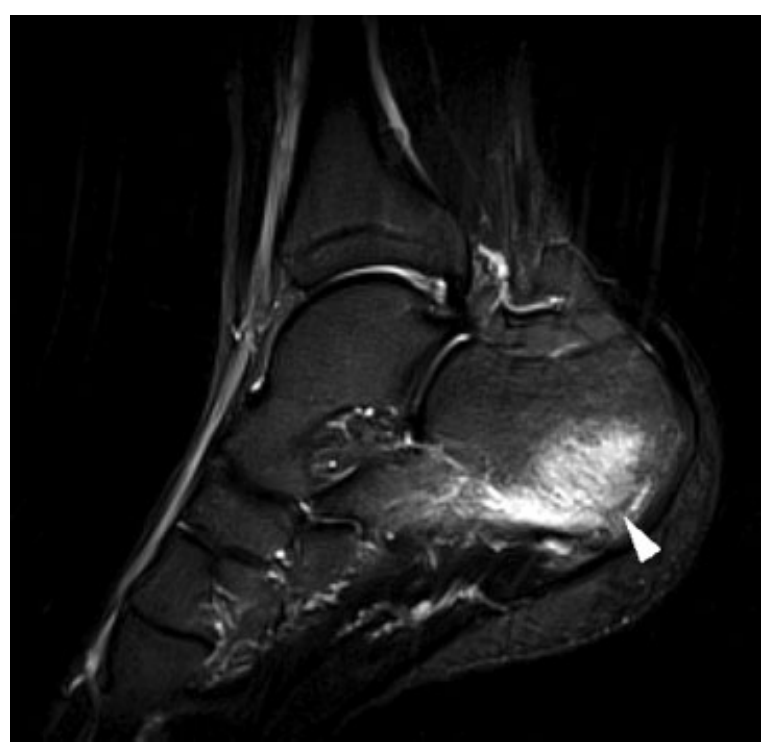

Figure 21 Calcaneal stress fracture. Sagittal short tau inversion recovery sequence showing bone edema with a subtle low signal fracture line parallel to the posterior cortex (arrowhead). fractures are associated with nonosseous calcaneonavicular coalition and are rare, comprising $\sim 1 \%$ of calcaneal fractures.

Navicular stress fractures tend to occur in sprinting and jumping athletes. Patients complain of insidious onset of pain or a cramping sensation brought on by activity. In the early stages patients may be able to continue running if the forefoot is not involved in foot strike. Navicular stress fractures are often difficult to diagnose on radiographs and can result in significant disability if the diagnosis is delayed..$^{41} \mathrm{MRI}$ is therefore recommended if there is a clinical suspicion. CT also has an important role in delineating and following up on these fractures. ${ }^{42}$ The fracture may be partial or complete and usually involves the relatively avascular central or lateral portion of the navicular in the sagittal plane, which is the site of maximum shear stress. The fracture may have a Y-shaped configuration. Cuneiform and cuboid stress fractures are uncommon but may be associated with plantar fascia injury, changes in gait, and large body habitus.

\section{MANAGEMENT}

Simple stress fractures of the foot and ankle settle with rest and protected weightbearing in an air-cast boot, followed by a graded return to training. The approximate time to full training is 4 to 8 weeks from initiation of treatment. Certain fractures such as those to the base of the second or fifth metatarsal and the navicular may require internal fixation.

\section{METATARSALGIA}

Pain within or around the metatarsophalangeal (MTP) joints (metatarsalgia) is a common problem with a wide differential diagnosis including trauma, Freiberg's infraction, tendinopathy, and Morton's neuroma. 


\section{Freiberg's Disease}

Freiberg's disease is a condition characterized by collapse of the second or third metatarsal head, thought to be related to repetitive trauma and avascular necrosis. It occurs more commonly in females and typically affects adolescents. On radiographs there is collapse and irregularity of the metatarsal head. On MRI a subchondral fracture line may be seen in the metatarsal head, in association with synovitis at the metatarsophalangeal joint. If an early diagnosis is made, then offloading the metatarsal head may be sufficient. If synovitis is a major feature, steroid injection may give pain relief. Surgery should be reserved for recalcitrant cases.

\section{Morton's Neuroma}

A Morton's neuroma is not a true neuroma but rather perineural fibrosis due to entrapment of the interdigital nerve at the level of the metatarsal heads. It most commonly occurs in the third, followed by the second interspace. Women are affected more than men. The typical presentation is of pain, with burning and tingling sensations. On lateral compression a click may be felt (Mulder's click).

\section{PATHOLOGY AND IMAGING}

On MRI, Morton's neuromas are best demonstrated on coronal T1-weighted images through the level of the metatarsal heads, appearing isointense to slightly hyperintense relative to muscle. On T2-weighted and STIR images Morton's neuromas tend to be hypointense, resulting in poor lesion conspicuity. If there is associated intermetatarsal bursitis, fluid signal is seen. Ultrasound is an excellent modality for assessing Morton's neuromas because the imaging findings can be correlated with symptoms. In the sagittal plane the lesion appears as a low signal rounded hypoechoic nodule that may be partly compressible. $^{43}$

\section{MANAGEMENT}

Some clinicians consider imaging unnecessary for diagnosis, but imaging can exclude other causes of metatarsalgia and can be used to guide therapeutic injection. Footwear modification and targeted cortisone injections are the main nonoperative measures. If symptoms persist, excision can be performed.

\section{Plantar Plate Injury}

Plantar plate insufficiency may result from wearing highheeled shoes, hypermobility, hyperextension injury, and overuse injury. Turf toe refers to an acute injury resulting from a severe hyperextension injury associated with playing sports on a hard surface such as artificial turf, with rupture of the plantar plate close to the distal insertion. The first or second metatarsophalangeal joints are usually affected. Following the injury, running and push-off is compromised. Long-term sequelae include hallux rigidus and hallux valgus.

\section{ANATOMY AND IMAGING}

The plantar plate is a fibrocartilaginous structure attaching the metatarsal neck to the base of the proximal phalanx, blending with the sesamoids and flexor hallucis brevis tendon to resist hyperextension and provide structural support. ${ }^{44}$ On ultrasound the plantar plate appears as a low echogenicity band with a grainy homogeneous texture. On MRI, the normal plantar plate is a smooth, curvilinear, low signal structure abutting the plantar aspect of the metatarsal head. Tears manifest as discontinuity of the plate with an area of increased T2 signal intensity. There may be associated bone edema, synovitis, flexor tendon sheath synovitis, and hyperextension of the proximal phalanx (Fig. 22).

\section{MANAGEMENT}

Most metatarsophalangeal joint injuries can be managed nonsurgically with insoles and strapping. More severe injuries may require long-term immobilization in a boot or cast.

\section{Sesamoiditis}

\section{PRESENTATION}

Mechanical overuse, stress fractures, osteochondritis, chondromalacia, and avascular necrosis of the hallucial

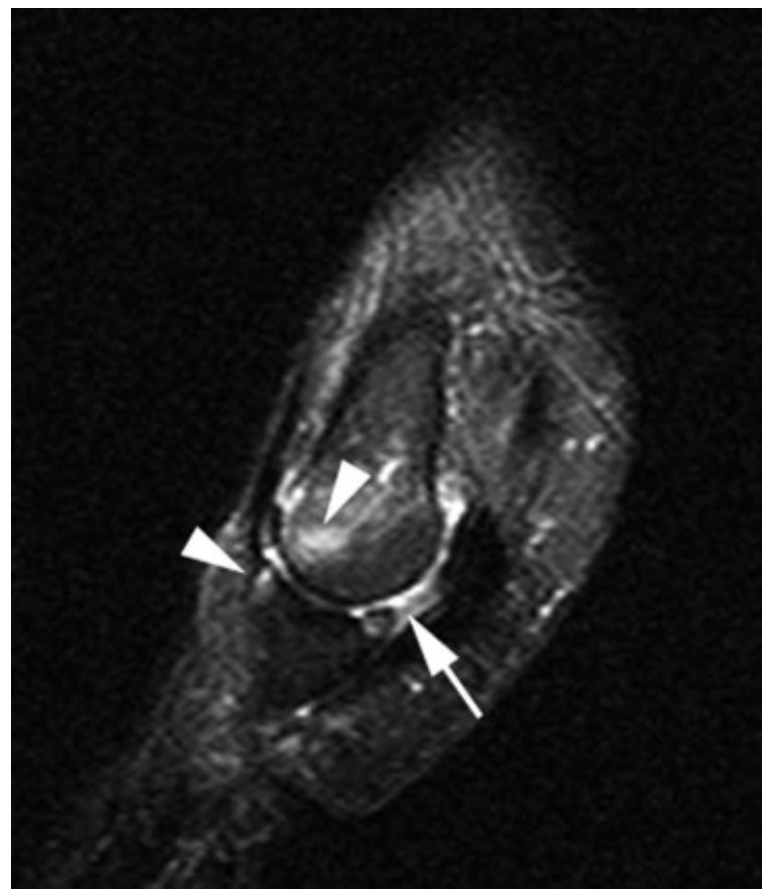

Figure 22 Turf toe. Sagittal short tau inversion recovery sequence showing a tear of the plantar plate (arrow), with bone edema on both sides of the metatarsophalangeal (arrowheads) joint. 


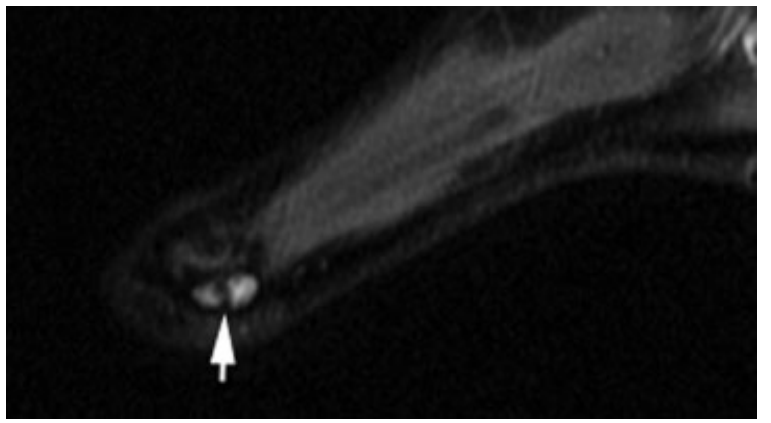

Figure 23 Sesamoiditis. Sagittal short tau inversion recovery sequence demonstrating a medial sesamoid fracture with associated bone edema (arrow). Notice slight malalignment of the fracture.

sesamoid bones belong to the same pathological spectrum, covered by the term sesamoiditis. The onset may follow repeated forefoot loading or acute trauma. Symptoms are more common in the medial sesamoid and in bipartite sesamoids, which occur in up to $33 \%$ of the population. ${ }^{44}$ On examination the pain is reproduced on weightbearing tiptoe activities, the FHL tendon is often tight, and movement of the first MTP is painful and restricted.

\section{ANATOMY AND IMAGING}

The hallux sesamoids are embedded within the medial and lateral slips of the flexor hallucis brevis tendon. The sesamoids absorb most of the weightbearing force of the medial forefoot. On radiographs the involved sesamoid may be sclerotic and fragmented, but there may be no obvious abnormality. Bipartite sesamoids can be difficult to differentiate from sesamoid fractures on all modalities. Fractures typically have sharp, uncorticated margins (Fig. 23). On MRI, painful sesamoids typically demonstrate bone edema on fluid-sensitive sequences. Osteonecrosis of the hallux sesamoids may occur secondary to fracture, dislocation, infection, or repetitive microtrauma. On MRI there is low signal change on all sequences. ${ }^{45}$

\section{MANAGEMENT}

The mainstay of management is to offload the sesamoid and to use orthotics. Ultrasound-guided steroid injection may help. Surgery should be reserved for recalcitrant cases because it may affect the biomechanics of the forefoot and can predispose to hallux valgus. Excision of both sesamoids invariably results in claw toe deformity and should be avoided.

\section{CONCLUSION}

Overuse injuries of the foot and ankle often cause pain and debility. Imaging plays a key role in the assessment, understanding, and management of these conditions. A good knowledge of the spectrum of overuse injuries is essential to ensure appropriate investigation and subsequent early treatment.

\section{REFERENCES}

1. Liu SH, Nuccion SL, Finerman G. Diagnosis of anterolateral ankle impingement. Comparison between magnetic resonance imaging and clinical examination. Am J Sports Med 1997;25(3):389-393

2. Robinson P. Impingement syndromes of the ankle. Eur Radiol 2007;17(12):3056-3065

3. Robinson P, Bollen SR. Posterior ankle impingement in professional soccer players: effectiveness of sonographically guided therapy. AJR Am J Roentgenol 2006;187(1): W53-58

4. Peace KA, Hillier JC, Hulme A, Healy JC. MRI features of posterior ankle impingement syndrome in ballet dancers: a review of 25 cases. Clin Radiol 2004;59(11):1025-1033

5. Koulouris G, Connell D, Schneider T, Edwards W. Posterior tibiotalar ligament injury resulting in posteromedial impingement. Foot Ankle Int 2003;24(8):575-583

6. Messiou C, Robinson P, O'Connor PJ, Grainger A. Subacute posteromedial impingement of the ankle in athletes: MR imaging evaluation and ultrasound guided therapy. Skeletal Radiol 2006;35(2):88-94

7. van Dijk CN, Tol JL, Verheyen CC. A prospective study of prognostic factors concerning the outcome of arthroscopic surgery for anterior ankle impingement. Am J Sports Med 1997;25(6):737-745

8. Farooki S, Yao L, Seeger LL. Anterolateral impingement of the ankle: effectiveness of MR imaging. Radiology 1998; 207(2):357-360

9. McCarthy CL, Wilson DJ, Coltman TP. Anterolateral ankle impingement: findings and diagnostic accuracy with ultrasound imaging. Skeletal Radiol 2008;37(3):209-216

10. Robinson P, White LM, Salonen D, Ogilvie-Harris D. Anteromedial impingement of the ankle: using MR arthrography to assess the anteromedial recess. AJR Am J Roentgenol 2002;178(3):601-604

11. Klein MA, Spreitzer AM. MR imaging of the tarsal sinus and canal: normal anatomy, pathologic findings, and features of the sinus tarsi syndrome. Radiology 1993;186(1):233-240

12. Anderson MW, Kaplan PA, Dussault RG, Hurwitz S. Association of posterior tibial tendon abnormalities with abnormal signal intensity in the sinus tarsi on MR imaging. Skeletal Radiol 2000;29(9):514-519

13. Oloff LM, Schulhofer SD, Bocko AP. Subtalar joint arthroscopy for sinus tarsi syndrome: a review of 29 cases. J Foot Ankle Surg 2001;40(3):152-157

14. Erickson SJ, Quinn SF, Kneeland JB, et al. MR imaging of the tarsal tunnel and related spaces: normal and abnormal findings with anatomic correlation. AJR Am J Roentgenol 1990;155(2):323-328

15. Saupe N, Mengiardi B, Pfirrmann CW, Vienne P, Seifert B, Zanetti M. Anatomic variants associated with peroneal tendon disorders: MR imaging findings in volunteers with asymptomatic ankles. Radiology 2007;242(2):509-517

16. O'Donnell P, Saifuddin A. Cuboid oedema due to peroneus longus tendinopathy: a report of four cases. Skeletal Radiol 2005;34(7):381-388

17. Schweitzer ME, Eid ME, Deely D, Wapner K, Hecht P. Using MR imaging to differentiate peroneal splits from other 
peroneal disorders. AJR Am J Roentgenol 1997;168(1):129133

18. Sobel M, Pavlov H, Geppert MJ, Thompson FM, DiCarlo EF, Davis WH. Painful os peroneum syndrome: a spectrum of conditions responsible for plantar lateral foot pain. Foot Ankle Int 1994;15(3):112-124

19. Brigido MK, Fessell DP, Jacobson JA, et al. Radiography and US of os peroneum fractures and associated peroneal tendon injuries: initial experience. Radiology 2005;237(1):235-241

20. Neustadter J, Raikin SM, Nazarian LN. Dynamic sonographic evaluation of peroneal tendon subluxation. AJR Am J Roentgenol 2004;183(4):985-988

21. Gluck GS, Heckman DS, Parekh SG. Tendon disorders of the foot and ankle, part 3: the posterior tibial tendon. Am J Sports Med 2010;38(10):2133-2144

22. Balen PF, Helms CA. Association of posterior tibial tendon injury with spring ligament injury, sinus tarsi abnormality, and plantar fasciitis on MR imaging. AJR Am J Roentgenol 2001;176(5):1137-1143

23. Mengiardi B, Zanetti M, Schöttle PB, et al. Spring ligament complex: MR imaging-anatomic correlation and findings in asymptomatic subjects. Radiology 2005;237(1):242-249

24. Mansour R, Teh J, Sharp RJ, Ostlere S. Ultrasound assessment of the spring ligament complex. Eur Radiol 2008;18(11):2670-2675

25. Lawson JP, Ogden JA, Sella E, Barwick KW. The painful accessory navicular. Skeletal Radiol 1984;12(4):250-262

26. Miller TT, Staron RB, Feldman F, Parisien M, Glucksman WJ, Gandolfo LH. The symptomatic accessory tarsal navicular bone: assessment with MR imaging. Radiology 1995;195(3):849-853

27. Mengiardi B, Pfirrmann CW, Vienne P, et al. Anterior tibial tendon abnormalities: MR imaging findings. Radiology 2005;235(3):977-984

28. Jeswani T, Morlese J, McNally EG. Getting to the heel of the problem: plantar fascia lesions. Clin Radiol 2009; 64(9):931-939

29. Berkowitz JF, Kier R, Rudicel S. Plantar fasciitis: MR imaging. Radiology 1991;179(3):665-667

30. Crawford F, Thomson C. Interventions for treating plantar heel pain. Cochrane Database Syst Rev 2003;(3):CD000416

31. Berndt AL, Harty M. Transchondral fractures (osteochondritis dissecans) of the talus. J Bone Joint Surg Am 2004;86$A(6): 1336$

32. De Smet AA, Ilahi OA, Graf BK. Reassessment of the MR criteria for stability of osteochondritis dissecans in the knee and ankle. Skeletal Radiol 1996;25(2):159-163
33. Mesgarzadeh M, Sapega AA, Bonakdarpour A, et al. Osteochondritis dissecans: analysis of mechanical stability with radiography, scintigraphy, and MR imaging. Radiology 1987;165(3):775-780

34. O'Loughlin PF, Heyworth BE, Kennedy JG. Current concepts in the diagnosis and treatment of osteochondral lesions of the ankle. Am J Sports Med 2010;38(2):392-404

35. Anderson MW, Greenspan A. Stress fractures. Radiology 1996;199(1):1-12

36. Kiuru MJ, Pihlajamaki HK, Hietanen HJ, Ahovuo JA. MR imaging, bone scintigraphy, and radiography in bone stress injuries of the pelvis and the lower extremity. Acta Radiol 2002;43(2):207-212

37. Gaeta M, Minutoli F, Scribano E, et al. CT and MR imaging findings in athletes with early tibial stress injuries: comparison with bone scintigraphy findings and emphasis on cortical abnormalities. Radiology 2005;235(2):553-561

38. Fredericson M, Bergman AG, Hoffman KL, Dillingham MS. Tibial stress reaction in runners. Correlation of clinical symptoms and scintigraphy with a new magnetic resonance imaging grading system. Am J Sports Med 1995;23(4):472481

39. Kiss ZS, Khan KM, Fuller PJ. Stress fractures of the tarsal navicular bone: CT findings in 55 cases. AJR Am J Roentgenol 1993;160(1):111-115

40. Sormaala MJ, Niva MH, Kiuru MJ, Mattila VM, Pihlajamäki HK. Stress injuries of the calcaneus detected with magnetic resonance imaging in military recruits. J Bone Joint Surg Am 2006;88(10):2237-2242

41. Burne SG, Mahoney CM, Forster BB, Koehle MS, Taunton JE, Khan KM. Tarsal navicular stress injury: long-term outcome and clinicoradiological correlation using both computed tomography and magnetic resonance imaging. Am J Sports Med 2005;33(12):1875-1881

42. Saxena A, Fullem B. Navicular stress fractures: a prospective study on athletes. Foot Ankle Int 2006;27(11):917-921

43. Redd RA, Peters VJ, Emery SF, Branch HM, Rifkin MD. Morton neuroma: sonographic evaluation. Radiology 1989; 171(2):415-417

44. Karasick D, Schweitzer ME. Disorders of the hallux sesamoid complex: MR features. Skeletal Radiol 1998;27(8):411-418

45. Fleischli J, Cheleuitte E. Avascular necrosis of the hallucial sesamoids. J Foot Ankle Surg 1995;34(4):358-365

46. Mintz DN, Tashjian GS, Connell DA, Deland JT, O'Malley M, Potter HG. Osteochondral lesions of the talus: a new magnetic resonance grading system with arthroscopic correlation. Arthroscopy 2003;19(4):353-359 